\title{
CICATRIZAÇÃO GÁSTRICA COM USO DO EXTRATO DA EUPHORBIA TIRUCALLI L.: ESTUDO EM RATOS
}

\author{
Gastric healing process with raw extract of Euphorbia tirucalli L.: study in rats
}

Orlando José dos SANTOS ${ }^{1}$, Francisco Felipe de CARVALHO-JÚNIOR ${ }^{2}$, Euler Nicolau SAUAIA-FILHO ${ }^{2}$, Rayan Haquim Pinheiro SANTOS ${ }^{3}$, Rennan Abud Pinheiro SANTOS ${ }^{2}$, Wilwana Guimarães BARBALHO ${ }^{3}$

Trabalho realizado no ${ }^{1}$ Departamento de Medicina II, Universidade Federal do Maranhão - UFMA; ${ }^{2}$ Hospital Universitário Presidente Dutra - UFMA, São Luís, MA; e ${ }^{3}$ Universidade Federal da Paraíba - UFPB, João Pessoa, PB, Brasil.

DESCRITORES - Fitoterapia. Estômago. Rato. Aveloz. Euphorbia.

\section{Correspondência:}

Orlando José dos Santos

E-mail: orlanddojs@hotmail.com

orlanddojs@hotmail.com

Fonte de financiamento: não há

Conflito de interesses: não há

Recebido para publicação: 16/04/2013 Aceito para publicação: 09/07/2013

HEADINGS - Phytotherapy. Stomach. Mouse. Aveloz, Euphorbia.
RESUMO - Racional - A utilização de plantas na prevenção e no tratamento de doenças é prática milenar. O aveloz (Euphorbia tirucalli) é uma planta originária da África e tem sido relacionada com efeitos antimicrobiano, antiulceroso, anticarcinogênico, antivirais, cicatrizante, antihelmíntico e antisifilítico. Objetivo - Avaliar o uso do extrato bruto de Euphorbia tirucalli no processo de cicatrização de estômago de camundongo. Métodos - Dezesseis camundongos da espécie Swiss, adultos, fêmeas foram submetidos à incisão longitudinal de $1 \mathrm{~cm}$ no corpo gástrico e síntese em plano único com pontos separados de polipropilene 6-0. Após o procedimento os animais foram distribuídos aleatoriamente em dois grupos de oito. Eles foram redistribuídos em quatro subgrupos: Aveloz (GA7) e Controle (GC7) com morte programada para $7^{\circ}$ dia de pós-operatório e Aveloz (GA14) e Controle (GC14) com morte programada para $14^{\circ}$ dia de pós-operatório. No seguimento o grupo GA utilizou-se $1 \mathrm{~mL}$ de solução hidroalcoólica do extrato bruto de Euphorbia tirucalli L. na concentração de $30 \mathrm{mg} / \mathrm{ml}$ por via oral através de gavagem e no GC, soro fisiológico 0,9\%, no mesmo volume e via. Após a morte, foi realizado o inventário da cavidade abdominal e procedeu-se a retirada do estômago, fixação no formol e enviado para a análise microscópica. Na análise comparativa entre os dois grupos foram avaliados parâmetros macroscópicos e microscópicos da cicatrização. Resultados - Não foram detectados sinais de peritonite, fístulas ou hematomas nos animal. Houve aderências do estômago, principalmente, com o fígado e omento, nos animais dos $7^{\circ}$ e $14^{\circ}$ dias do período pós-operatório nos dois grupos. A análise dos parâmetros histológicos não demonstrou diferença estatisticamente significante em nenhum dos parâmetros avaliados. Conclusão - A avaliação do uso do extrato bruto de Euphorbia tirucalli L. em cicatrização de lesões em estômago de camundogos mostrou equivalência em comparação ao grupo controle.

ABSTRACT - Background - The use of plants in the prevention and treatment of disease is age-old practice. The aveloz (Euphorbia tirucalli) is a plant native of Africa and has been associated with antimicrobial, antiulcers, anticarcinogenic, antiviral, healing, anti-helminthic, antisiphilitic effects. Aim - To analyze the effect of the crude extract of Euphorbia tirucalli L. in the stomach healing process of mice. Methods - Sixteen Swiss mice, adult females were subjected to $1 \mathrm{~cm}$ longitudinal incision in the gastric body and sutured with 6-0 polypropylene stitches. After the procedure, the animals were randomly divided into two groups of eight animals. These were redistributed into four subgroups: Aveloz (GA7) and Control (CG7) with programmed death for 7th day postoperatively and Aveloz (GA14) and Control (GC14) with programmed death for 14 days postoperatively. The group GA used $1 \mathrm{ml}$ of hydroalcoholic solution of the crude extract of Euphorbia tirucalli at $30 \mathrm{mg} / \mathrm{ml}$ orally by gavage route and the CG, $0.9 \%$ saline solution at the same volume and route. After death, the inventory of the abdominal cavity was conducted and the stomach removal was performed, fixing in formalin and sent for microscopic analysis. In the comparative analysis between the two groups were evaluated the macroscopic and microscopic parameters of healing. Results - There were no signs of peritonitis, fistulas or hematomas in the animals. There were adhesions of the stomach, especially with the liver and omentum in the animals at 7 and 14 days postoperatively in both groups. The analysis of histological parameters showed no statistically significant difference between groups in any of the parameters evaluated. Conclusion - The evaluation of the use of the crude extract of Euphorbia tirucalli L. on stomach wound healing in mice showed equivalence in comparison to the control group. 


\section{INTRODUÇÃO}

B rasil está entre os países com a maior diversidade ambiental que existe. No entanto, a pesquisa relacionada com os medicamentos fitoterápicos está ainda abaixo do potencial e dos benefícios que eles têm para o conhecimento científico mundial ${ }^{9}$. Apesar disso, atualmente muito se tem evoluído na busca de substâncias de efeitos anticâncer, antimicrobianos, cicatrizante, entre outros.

Espécies da Euphorbia têm sido descritas e utilizadas na medicina popular como antimicrobiano, antiúlceras, anticancerígenas, antivirais, cicatrizante, anti-helmínticos e anti-sifilíticos ${ }^{4,5,7,14}$. Euphorbia tirucalli L. (Euphorbiaceae) é conhecida no Brasil como "aveloz".

Alguns autores têm estudado os benefícios cicatrizantes de espécies Euphorbia, e essa propriedade é explicada pela ação de fitoconstituintes desta planta, que aumentam o colágeno da matriz extracelular, como taninos e flavonóides ${ }^{3,10}$.

O objetivo deste estudo foi avaliar o efeito do extrato bruto de E. tirucalli no processo de cicatrização de lesões no estômago de ratos, enfatizando suas características macroscópicas e histológicas.

\section{MÉTODO}

O projeto foi avaliado e aprovado pelo Comitê de Ética em Pesquisa da Universidade Federal do Maranhão (UFMA), sob o protocolo $n{ }^{\circ}$ 00386/2004. $O$ estudo seguiu as diretrizes para pesquisas com animais, tal como estabelecido pelo Colégio Brasileiro de Experimentação Animal (COBEA).

A amostra foi composta de 16 camundongos Swiss machos (Swiss Webster, Rodentia Mammalia), fornecidos pelo Biotério da UFMA. Eles estavam entre 40 e 60 dias de idade (idade média de 46 dias). $O$ peso era entre $24 \mathrm{~g}$ e $30 \mathrm{~g}$ (peso médio de 25,3 g). Eles foram mantidos em grupos de quatro por gaiola-padrão para a espécie no Laboratório de Pesquisa do Departamento de Fisiologia, onde o ciclo claro-escuro foi de 12 horas e a umidade era a mesma que em ambiente normal, sem qualquer regulação artificial. A temperatura foi constante de $20 \pm 2^{\circ}$ C. Os animais foram alimentados com ração comercial padrão e livre acesso à água durante todo o experimento.

Cada animal foi submetido à anestesia com cloridrato de xilazina à $2 \%\left(5 \mathrm{mg} / \mathrm{kg}\right.$, IM - Kensol $\left({ }^{\circledR}\right)$ e cloridrato de quetamina à $5 \%(22 \mathrm{mg} / \mathrm{kg}$, IM -Vetanarcol ()$)$, conjuntamente na mesma seringa.

Os animais foram distribuídos aleatoriamente em dois grupos de oito, um grupo controle (GC) e um grupo Aveloz (GA). Cada grupo foi redistribuído em dois subgrupos GC7 e GC14 e subgrupos GA7 e GA14, conforme os dias da morte, programada para o $7^{\circ} \mathrm{e}$ $14^{\circ}$ dias de pós-operatório, respectivamente.

$\mathrm{O}$ ato operatório seguiu metodização para os animais de ambos os grupos. Após anestesiado cada camundongo foi posicionado em decúbito dorsal e imobilizado e preparado campo cirúrgico com técnica asséptica. Realizou-se laparotomia mediana longitudinal a partir de $1 \mathrm{~cm}$ abaixo do processo xifóide, estendendose por $3 \mathrm{~cm}$ caudalmente; procedeu-se a diérese da pele e do tecido celular subcutâneo com o bisturi lâmina $n^{\circ}$ 15 e do plano musculoaponeurótico e peritônio com tesoura; inspecionou-se a cavidade abdominal, fez-se a identificação e exteriorização do estômago e realizouse incisão longitudinal de $1 \mathrm{~cm}$ de comprimento ao maior eixo do mesmo na parede anterior do corpo gástrico, equidistante da pequena e grande curvaturas envolvendo todos os planos e sutura da lesão com quatro pontos separados com fio polipropileno azul (Prolene ${ }^{\circledR}$ Ethicon) 6-0 com agulha circular atraumática de $1,3 \mathrm{~cm}$. Posteriormente realizou-se síntese do peritônio, plano musculoaponeurótico e pele, de forma contínua com fio

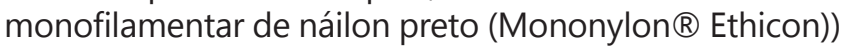
5-0 com agulha circular cortante de $2,5 \mathrm{~cm}$. Neste momento fez-se analgesia com dipirona, $25 \mathrm{mg} / \mathrm{kg} / \mathrm{IM}$.

Após a recuperação anestésica, cada animal dos subgrupos controle (GC7 e GC14) recebeu via gavagem solução salina à $0,9 \%$ diariamente. Nos animais dos subgrupos aveloz (GA7 e GA14), administrou-se 100 mg/kg do extrato bruto da Euphorbia tirucalli L. na concentração de $100 \mathrm{mg} / \mathrm{ml}$, pela manhã obedecendo os dias previamente estabelecidos de observação. Os animais foram colocados em suas gaiolas com livre acesso à água e ração, acondicionados nas mesmas condições de temperatura e luminosidade do pré-operatório. No seguimento foram avaliados parâmetros clínicos diariamente.

Na data programada de morte, os animais receberam dose letal de cloridrato de xilazina à $2 \%(20 \mathrm{mg} / \mathrm{kg} / \mathrm{IM})$ e cloridrato de quetamina à $5 \%(30 \mathrm{mg} / \mathrm{kg} / \mathrm{IM})$, sendo ambos aplicados conjuntamente na mesma seringa.

Após a morte foi feita a inspeção da cicatriz abdominal, avaliou-se a presença ou não de hematoma, infecção de sítio operatório e deiscências da ferida. Realizou-se em seguida a abertura da parede abdominal mediante duas incisões transversas e uma longitudinal ligando as anteriores, distando 1 $\mathrm{cm}$ à esquerda da cicatriz mediana decorrente do ato operatório prévio. Avaliou-se a presença de aderências perigástricas graduando-as segundo o escore de Nair, como também os aspectos da mucosa gástrica ${ }^{11,16}$.

Procedeu-se a retirada do estômago, sendo ele fixado em formol a $10 \%$ no interior de frascos individuais e enviados ao estudo histopatológico. O patologista desconhecia o grupo correspondente a cada frasco.

Utilizou-se um microscópio tetraocular, no qual o campo histológico de cada lâmina da ferida da mucosa gástrica foi avaliado, utilizando-se as objetivas de 5,10 e 40 vezes de aumento e ocular de 10 vezes. Os critérios histológicos incluíram: inflamação aguda, inflamação crônica inespecífica, proliferação fibroblástica, colagenização e epitelização da ferida, classificados em leve, moderado e intenso de acordo com a gradação de intensidade em cruzes. 
Utilizou-se o programa Biostat 5.0 (Microsoft), os testes t de Student e Mann-Whitney, para análise dos dados que se obteve; o valor-p era significante quando $p<0,05$.

\section{RESULTADOS}

$\mathrm{Na}$ avaliação clínica todos os animais evoluíram de forma semelhante, com boa aceitação da dieta e ausência de secreções, abaulamento, retração, deiscência ou fístulas na ferida operatória.

A análise da cavidade abdominal dos animais em estudo mostrou que $25 \%$ do subgrupo GC7 apresentou aderências omentais e hepáticas, enquanto $50 \%$ do subgrupo GA7 revelaram a mesma alteração. Nos subgrupos cuja morte foi realizada no $14^{\circ}$ dia de observação, tais alterações corresponderam a 50\% no subgrupo controle e $75 \%$ dos animais do subgrupo aveloz. Não foi notado durante o tempo de estudo qualquer indicativo de peritonite ou outras coleções.

No âmbito da avaliação histológica, principal vertente desse estudo, os resultados obtidos encontramse discriminados nas tabelas de 1 a 3 . Somando-se ao restante da avaliação histológica, pode-se constatar a ausência, em todas as peças analisadas de hemorragia, atrofia glandular e metaplasia intestinal.

Aplicando os métodos estatísticos sobre as variantes classificatórias conseguidas a partir do estudo histopatológico, houve diferença tanto entre os subgrupos do $7^{\circ}$ e $14^{\circ}$ dias em comparação do aveloz com o grupo controle, sem no entanto ser estatisticamente significante(Tabelas 1-3).

TABELA 1 - Avaliação histológica (gastrite crônica, atividade inflamatória, células mononucleares e polimorfonucleares) dos parâmetros de cicatrização de gastrorrafia em animais tratados com extrato bruto de Euphorbia tirucalli L. e controle (solução salina 0,9\%).

\begin{tabular}{|c|c|c|c|c|}
\hline $\begin{array}{c}\text { Variáveis } \\
\text { Histolóqicas }\end{array}$ & \multicolumn{4}{|c|}{ Dias/Grupos } \\
\hline \multirow[t]{2}{*}{$/ p$} & \multicolumn{2}{|c|}{7 dias } & \multicolumn{2}{|c|}{14 dias } \\
\hline & Aveloz & Controle & Aveloz & Controle \\
\hline \multirow{4}{*}{$\begin{array}{c}\text { Gastrite crônica } \\
\text { /p }\end{array}$} & $+(1)$ & $+(1)$ & $+(2)$ & $+(1)$ \\
\hline & $++(3)$ & $++(3)$ & $++(2)$ & $++(1)$ \\
\hline & & & & $+++(2)$ \\
\hline & \multicolumn{2}{|c|}{0,124} & \multicolumn{2}{|c|}{0,500} \\
\hline \multirow{4}{*}{$\begin{array}{c}\text { Atividade } \\
\text { Inflamatória } \\
\text { /p }\end{array}$} & $+(1)$ & $+(1)$ & $+(3)$ & - (1) \\
\hline & $++(3)$ & $++(2)$ & $++(1)$ & $++(1)$ \\
\hline & & $+++(1)$ & & $+++(2)$ \\
\hline & \multicolumn{2}{|c|}{0,124} & \multicolumn{2}{|c|}{0,500} \\
\hline \multirow{3}{*}{$\begin{array}{c}\text { Células } \\
\text { Mononucleares } \\
\text { /p }\end{array}$} & $++(4)$ & $+(1)$ & $+(3)$ & $+(1)$ \\
\hline & & $++(3)$ & $++(1)$ & $++(1)$ \\
\hline & & & & $+++(2)$ \\
\hline \multirow{4}{*}{$\begin{array}{l}\text { Polimorfonucleares } \\
\qquad / p\end{array}$} & \multicolumn{2}{|c|}{0,193} & \multicolumn{2}{|c|}{0,281} \\
\hline & - (1) & $-(1)$ & $+(4)$ & $-(1)$ \\
\hline & $+(1)$ & $+(1)$ & & $+(1)$ \\
\hline & 0,281 & $+++(2)$ & & $+++(2)$ \\
\hline
\end{tabular}

Legenda: As variáveis foram classificadas como ausente $(-)$, discreta $(+)$, moderada $(++)$ ou intensa $(+++)$, com base na intensidade relativa de gastrite crônica, atividade inflamatória, células mononucleares e polimorfonucleares por coloração H\&E. O número entre parênteses corresponde ao de animais em cada classificação.
TABELA 2 - Avaliação histológica (reação gigantocelular, proliferação fiboblástica, angiogênese e crosta fibrinoleucocitária) dos parâmetros de cicatrização de gastrorrafia em animais tratados com extrato bruto de Euphorbia tirucalli L. e controle (solução salina 0,9\%).

\begin{tabular}{|c|c|c|c|c|}
\hline $\begin{array}{l}\text { Variáveis } \\
\text { Histológicas }\end{array}$ & \multicolumn{4}{|c|}{ Dias/Grupos } \\
\hline$/ p$ & \multicolumn{2}{|c|}{7 dias } & \multicolumn{2}{|c|}{14 dias } \\
\hline & Aveloz & Controle & Aveloz & Controle \\
\hline \multirow{3}{*}{$\begin{array}{l}\text { Reação } \\
\text { Gigantocelular } \\
/ p\end{array}$} & $-(2)$ & - (1) & - (1) & $-(2)$ \\
\hline & $+(2)$ & $+(3)$ & $+(3)$ & $+(2)$ \\
\hline & \multicolumn{2}{|c|}{0,500} & \multicolumn{2}{|c|}{0,281} \\
\hline \multirow{4}{*}{$\begin{array}{l}\text { Proliferação } \\
\text { Fibroblástica } \\
\qquad / p\end{array}$} & - (1) & $+(1)$ & $+(3)$ & - (1) \\
\hline & $+(3)$ & $++(3)$ & $++(1)$ & $+(2)$ \\
\hline & \multirow{2}{*}{\multicolumn{2}{|c|}{0,281}} & & $+++(1)$ \\
\hline & & & \multicolumn{2}{|c|}{0,156} \\
\hline \multirow{4}{*}{ Angiogênese/p } & $+(4)$ & $+(3)$ & $+(3)$ & - (1) \\
\hline & & $++(1)$ & & $+(2)$ \\
\hline & & & & $+++(1)$ \\
\hline & \multicolumn{2}{|c|}{0,124} & \multicolumn{2}{|c|}{0,281} \\
\hline \multirow{3}{*}{$\begin{array}{c}\text { Crosta } \\
\text { Fibrinoleucocitária } \\
/ \mathrm{p}\end{array}$} & $-(2)$ & $-(2)$ & - (1) & $-(2)$ \\
\hline & $+(2)$ & $+(2)$ & $+(3)$ & $+(2)$ \\
\hline & \multicolumn{2}{|c|}{0,2819} & \multicolumn{2}{|c|}{0,500} \\
\hline \multicolumn{5}{|c|}{$\begin{array}{l}\text { Legenda: As variáveis foram classificadas como ausente }(-) \text {, discreta }(+) \text {, } \\
\text { moderada }(++) \text { ou intensa }(+++) \text {, com base na intensidade relativa de } \\
\text { reação gigantocelular, proliferação fiboblástica, angiogênese e crosta } \\
\text { fibrinoleucocitária por coloração H\&E. O número entre parênteses corresponde } \\
\text { ao número de animais em cada classificação. }\end{array}$} \\
\hline
\end{tabular}

TABELA 3 - Avaliação histológica (presença de hiperplasia foveolar, folículos linfóides e alterações epiteliais reativas/reparativas) dos parâmetros de cicatrização de gastrorrafia em animais tratados com extrato bruto de Euphorbia tirucalli L.e controle (solução salina 0,9\%)

\begin{tabular}{|c|c|c|c|c|}
\hline Variáveis & \multicolumn{4}{|c|}{ Dias/Grupos } \\
\hline \multirow[t]{2}{*}{$/ p$} & \multicolumn{2}{|c|}{7 dias } & \multicolumn{2}{|c|}{14 dias } \\
\hline & Aveloz & Controle & Aveloz & Controle \\
\hline \multirow{3}{*}{$\begin{array}{l}\text { Hiperplasia Foveolar } \\
\qquad / p\end{array}$} & $-(2)$ & - (1) & $-(1)$ & $-(2)$ \\
\hline & $+(2)$ & $+(3)$ & $+(3)$ & $+(2)$ \\
\hline & \multicolumn{2}{|c|}{0,500} & \multicolumn{2}{|c|}{0,281} \\
\hline \multirow{3}{*}{$\begin{array}{l}\text { Folículos Linfóides } \\
\qquad / \mathrm{p}\end{array}$} & $-(2)$ & - (4) & - (s) & $-(4)$ \\
\hline & $+(2)$ & & $+(2)$ & \\
\hline & \multicolumn{2}{|c|}{0,124} & \multicolumn{2}{|c|}{0,124} \\
\hline \multirow{3}{*}{$\begin{array}{l}\text { Alterações Epiteliais } \\
\text { Reativas/ Reparativas } \\
\text { /p }\end{array}$} & $+(4)$ & $+(4)$ & - (1) & $+(4)$ \\
\hline & & & $+(3)$ & \\
\hline & \multicolumn{2}{|c|}{0,281} & \multicolumn{2}{|c|}{0,500} \\
\hline
\end{tabular}

Legenda: As variáveis foram classificadas como ausente $(-)$, discreta $(+)$, moderada $(++)$ ou intensa $(+++)$, com base na intensidade relativa da presença de hiperplasia foveolar, folículos linfóides e alterações epiteliais reativas/ reparativas por coloração H\&E. O número entre parênteses corresponde ao de animais em cada classificação.

\section{DISCUSSÃO}

O efeito do extrato da Euphorbia tirucalli L. na cicatrização ainda não foi demonstrado cientificamente, apesar de ser usado na medicina popular como cicatrizante há longo tempo. Este fato leva à proposição deste estudo, e ao modelo experimental aqui utilizado. No entanto, várias propriedades farmacológicas foram demonstradas em trabalhos experimentais como o seu efeito anti-bacteriano, molucicida, anti-herpético e anti-mutagênico ${ }^{2,6,8,12,17}$. 
A gastrorrafia foi executada no corpo, equidistantemente da pequena e grande curvaturas em plano único e suturado com três pontos separados, por ser esta técnica habitualmente utilizada na literatura, de fácil execução e segura. A escolha do fio de polipropileno 6-0 foi pautada na sua força tênsil e resistência na confecção da sutura e pouca reação inflamatória; e, por estes motivos, ele é recomendado frequentemente em estudos semelhantes.

A sutura da parede abdominal foi avaliada diariamente. Nenhum dos animais apresentou deiscência e nem infecção. Vários graus de aderências foram vistos, sendo que o índice de aderências cresceu com o aumento do tempo de pós-operatório. Estes fatos já foram também reconhecidos por outros autores; contudo, eles não interferiram com as anastomoses que puderam ser analisadas com isenção de intercorrências ${ }^{13}$.

No referente à escolha dos animais, os camundongos foram os eleitos, pela maior facilidade de transporte e manuseio, pela alta resistência às infecções e para maior representatividade no analisar com outros trabalhos com objetivos semelhantes, pois os animais de pequeno porte são os mais presentes neste tipo de estudo. Exemplos são os de Silva et al. ${ }^{13}$ que pesquisou as propriedades cicatrizantes da Passiflora edulis (maracujá) em gastrorrafias de ratos e de Santos et al. ${ }^{15}$ que usou ratos adultos para testar possíveis efeitos pró-regenerativos do extrato de Schinus terebinthifolius Raddi (aroeira).

Escolheram-se os períodos de morte dos camundongos no $7^{\circ}$ e $14^{\circ}$ dias de pós-operatório para que se pudesse estudar a cicatrização gástrica em suas fases mais posteriores, contrapondo-se à maioria dos experimentos que utilizaram $\circ 3^{\circ}$ e $\circ 7^{\circ}$ dias. Exemplos são os de Batista et al. ${ }^{1}$ que avaliaram a ação regenerativa do extrato aquoso de Orbignya phalerata (babaçu) em lesões gástricas, e de Silva et al. ${ }^{15}$ no estudo morfológico e tensiométrico de gastrorrafias em ratos usando o extrato de Passiflora edulis.

A via de aplicação do extrato por gavagem, baseouse na maior facilidade na realização das administrações diárias, para se evitar absorção mais rápida, manter a ação protetora da biotransformação hepática (primeira passagem), fatores protetores estes que não existiriam se fosse optada pela via parenteral. A via intra-peritoneal foi escolhida por alguns trabalhos, como o de Silva et al. ${ }^{15}$ que realizaram estudo morfológico com extrato de Passiflora edulis em gastrorrafias. A preocupação na manutenção destes elementos de defesa se faz necessária devido ao fato de existirem poucos trabalhos sobre a toxicidade dos derivados vegetais da espécie alvo.

O estudo histopatológico adotou como método de coloração a $\mathrm{H} \&$ E que foi o padrão para outros experimentos com aroeira, o babaçu, pião roxo e maracujá1,2,13,15.

Quanto aos resultados obtidos pode-se inferir que houve incidência $25 \%$ maior de aderências (gastrohepáticas e gastroepiplóicas) nos subgrupos dos casos em comparação com os subgrupos controle correspondentes; no entanto, na análise histológica não se notou qualquer diferencial estatisticamente relevante no tocante às variáveis estudadas. Portanto, o processo fibrótico que originou as aderências citadas não mantém relação ampla e direta com um favorecimento à cicatrização das gastrorrafias, até mesmo porque tal melhoria não foi notada.

\section{CONCLUSÃO}

A avaliação do uso do extrato bruto de Euphorbia tirucalli L. em cicatrização de lesões em estômago de camundogos mostrou equivalência no em comparação ao grupo controle.

\section{REFERÊNCIAS}

1. Batista CP, Torres OJM, Matias JEF, Moreira ATR, Colman D, Lima JHF, Macri MM, Rauen RJ Jr, Ferreira LM, de Freitas AC: Effect of watery extract of Orbignya phalerata (babassu) in the gastric healing in rats: morfologic and tensiometric study. Acta Cir Bras 2006, 21:26-32.

2. Betancur-Galvis LA, Morales GE, Forero JE, Roldan J: Cytotoxic and Antiviral Activities of Colombian Medicinal Plant Extracts of the Euphorbia genus. Mem Inst O Cruz 2002, 97:541-546.

3. Goyal M, Nagori BP, Sasmal D: Wound healing activity of latex of Euphorbia caducifolia. J Ethnopharmacol 2012, 144:786-790.

4. Hecker E: Co-carcinogenic principles from seed oil of Croton tiglium and other Euphorbiaceae. Cancer Res 1968, 28:2338-2349.

5. Jahan N, Khalil Ur R, Ali S, Bhatti IA: Antimicrobial Potential of Gemmomodified Extracts of Terminalia arjuna and Euphorbia tirucalli. Int J Agric Biol 2011, 13:1001-1005.

6. Jurberg P, Cabral Neto JB, Schall VT: Molluscicide activity of the "Avelós" plant ( Euphorbia tirucalli, L. ) on Biomphalaria glabrata, the mollusc vector of schistosomiasis. Mem Inst O Cruz 1985, 80:423427.

7. Khan A, Ahmed Z, Kazml N, Malik A: Further Triterpenes from the Stem Bark of Euphorbia tirucalli. Planta Med 1987, 53:577.

8. Lirio LG, Hermano ML, Fontanilla MQ: Antibacterial activity of medicinal plants from the Philippines. Pharm Biol 1998, 36:357-359.

9. Malafaia O, Campos ACL, Torres O, Goldenberg S: Phytotherapy and surgical wound healing. Acta Cir Bras 2006, 21:1.

10. Omale J, Emmanuel TF: Phytochemical composition, bioactivity and wound healing potential of Euphorbia heterophylla (Euphorbiaceae) leaf extract. IJBPR 2010, 1:54-63.

11. Qasim Khan A, Rasheed T, Najam-ul-Hussain Kazmi S, Ahmed Z, Malik A: Cycloeuphordenol, a new triterpene from Euphorbia tirucalli. Phytochemistry 1988, 27:2279-2281.

12. Rezende J, Rodrigues S, Jabor I, Pamphile J, Rocha C: Efeito antimutagênico do látex de Euphorbia tirucalli no sistema metionina em Aspergillus nidulans. Acta Sci 2004, 26:481-484.

13. Santos OJ, Ribas Filho JM, Czeczko NG, Castelo Branco Neto ML, Naufel C Jr, Ferreira LM, Campos RP, Moreira H, Porcides RD, Dobrowolski S: Evaluation of the aroeira (Schinus terebinthifolius Raddi) extract on the healing process of gastroraphy in rats. Acta Cir Bras 2006, 21:39-45.

14. Silva ACP, Faria DEP, Borges NBES, Souza IA, Peters VM, Guerra MdO. Toxicological screening of Euphorbia tirucalli L.: Developmental toxicity studies in rats. J Ethnopharmacol 2007, 110:154-159.

15. Silva JRS, Campos ACL, Ferreira LM, Aranha Júnior AA, Thiede $A$, Zago Filho LA, Bertoli LC, Ferreira M, Trubian PS, Freitas AC: Extract of Passiflora edulis in the healing process of gastric sutures en rats: a morphological and tensiometric study. Acta Cir Bras 2006, 21:52-60.

16. SK N, IK B, AL A: Role of proteolytic enzyme in the prevention of postoperative intraperitoneal. Arch Surg 1974, 108:849-853.

17. Tiwari S, Singh P, Singh A: Toxicity of Euphorbia tirucalli Plant Against Freshwater Target and Non- target Organisms. Pakistan J Biol Sci 2003, 6:1423-1429. 